\title{
Prevalence of Entamoeba histolytica amongst infants with diarrhoea visiting the University of Abuja Teaching Hospital
}

\author{
Balarabe-Musa, B. and Onyeagba, K. D. \\ Department of Biological Sciences University of Abuja, Nigeria
}

Accepted November, 2020 and Published December, 2020

\begin{abstract}
Amoebiasis is one of the major causes of morbidity and mortality worldwide, especially in developing countries because of lack of safe portable water and low level of hygiene. In Nigeria, amoebiasis is prevalent and widespread. The aim of our study was to estimate the prevalence ratio of E. histolytica among infants aged 1 to 59 months admitted at the University of Abuja Teaching Hospital, Gwagwalada, Abuja. The distribution of the infection was reported to relate more with inadequate environmental sanitation, poor personal hygiene and climate. The epidemiology, clinical features and causative agents of diarrhoea were investigated in 100 children aged 1-59 months visiting the University of Abuja Teaching Hospital. One hundred stool samples were collected and examined. The use of direct smear and floatation methods were employed to analyze the prevalence of Entamoeba histolytica in diarrhoeal illness across gender, age, weight and stool appearance of the patients. Out of the one hundred stool samples screened $12 \%$ were positive for the parasite. Females were more infected (12.5\%) than the males $(11.4 \%)$, but there was no significant association between prevalence and gender $(P>0.05)$. Children within the age group of 1 to 12 months old had the highest prevalence rate (20.0\%). There was a significant difference in the prevalence of Entamoeba histolytica among the age groups $(p<0.05)$. Children that weighed less than $15 \mathrm{~kg}$ had the highest prevalence of Entamoeba histolytica (25.0\%). There was a positive correlation between the prevalence and weight $(p<0.05)$. Prevalence rate of $16.0 \%$ was recorded for watery and bloody stool. There was a positive correlation between the prevalence of Entamoeb a histolytica and stool characteristics $(p<0.05)$. Hence this study analyzes the pattern, morbidty, occurrence and the preventibve measures to enact in tackling diarrhoeal illnesses. This study also aims to enlighten the public especially nursing mothers on the need to maintain proper hygiene in other to prevent contamination of diarrhoeal illness. Entamoeba histolytica can be a re-emerging serious infection when it finds favorable environmental conditions and host factors which are mainly attributed to poor hygiene in this study. This may occur in any area of the world with the same risk factors. Owing to the findings of this research, public health interventions such as the provision of clean water, community health education, observation of food hygiene, and maintenance of functioning sanitation systems are recommended towards controlling the infection.
\end{abstract}

Key words: Prevalence; Entamoeba histolytica; Infants; Diarrhoea.

\section{*Corresponding Author}

Email: onyeagbakosi001@gmail.com 


\section{INTRODUCTION}

In 2011, diarrhoea accounted for 700,000 deaths in children under five years of age (worldwide), making it the second leading cause of child mortality [1] Amoebiasis is prevalent worldwide and is common in children of the developing world. Entamoeba histolytica is associated with diarrhoea alternating with periods of constipation. Also, invasive parasite infection can cause severe amoebic dysentery [2] An estimate of 780 million individuals lack access to safe drinking water and about 2.5 billion lack improved sanitation and a large percentage of these individuals are seen in the developing countries. Each episode of diarrhoea deprives the child of the nutrition necessary for growth, as a result, diarrhoea is a major cause of malnutrition and malnourished children are most likely to fall ill from diarrhea.[3] Entamoeba histolytica is an aerobic parasitic protozoan belonging to genus entamoeba and an etiology agent of Amoebiasis. Entamoeba histolytica is pathogenic in the caecum and colon of human being.[4] Entamoeba histolytica is the most unique among the Amoebas because of its ability to hydrolyse host tissue. It can be highly virulent and invasive organism causing diarrhoea.

The distribution of the infection was reported to relate more with inadequate environmental sanitation, poor personal hygiene and climate. A study in Brazil identified place of residence, age, ingestion of raw vegetables, and drinking water quality as important risk factors.[5]

Amoebiasis is acquired through the faecal oral route by consumption of food, water or drink contaminated with cyst of the parasite.[4] Licking or sucking of faecally contaminated hands have been documented to introduce the infection to humans. Illegal disposed waste within and around human, immediate environment, open type latrine, unsafe drinking water and Improper hand washing has really promoted and increased diarrhoea and cases of amoebic dysentery.[6]

The majority of diarrhoea diseases can be prevented by implementing water sanitation and hygiene (WASH- programmes), which all aim at interrupting faecal-oral transmission pathways, commonly referred to as the five " $F$ "(Fluids, Fields, Flies, Fingers and Food).[7] Early detection and treatment are therefore key elements in public health Interventions, not only to manage individual cases but also to prevent the transmission of the disease to the rest of the population. After the observation of a considerable number of infants admitted to the University of Abuja Teaching Hospital, Gwagwalada Abuja, with gastroenteritis caused by Entamoeba histolytica, we decided to conduct this study to assess the prevalence, the epidemiology and risk factors for the problem of severe amebiasis necessitating hospitalization of infants and children of our locality, and also to add to the already existing pool of information regarding diarrhoeal illness in tropical Africa.

\section{MATERIALS AND METHODS}

\section{Study Area}

This study was carried out at the University of Abuja Teaching Hospital Gwagwalada, in the Federal Capital Territory of Nigeria.

Gwagwalada, being one of the six local government area councils of the Federal Capital Territory of Nigeria is located about $55 \mathrm{~km}$ away from the Federal Capital City. It lies on Latitude $8^{0} 55^{1}$ north of the equator and $9^{0} 00^{\prime}$ longitude east and $7^{\circ} 05^{\prime}$ east. The area covers a total of $65 \mathrm{sq} \mathrm{km}$ located at centre of a very fertile area with abundance of grasses. The hot season lasts for two and half months, from January 29 to April 12, with an average daily high temperature above $90^{\circ} \mathrm{F}$. The cool season lasts for three and half months, from June 21 to 
October 6, with an average daily high temperature below $83^{\circ} \mathrm{F}$. [8]

\section{Sample Collection}

Prior to the commencement of the research work, permission was sought from the hospital authorities and the parents of the children were informed. A total of 100 stool samples were collected from infants between the age bracket of 1 month and 59 months at the University of Abuja Teaching Hospital, Gwagwalada, Abuja.

The stool samples were collected with the assistance of hospital nurses, about $20 \mathrm{~g}$ of samples were collected into labeled, sterile, plastic specimen bottle for each diarrhoea patient. Structured questionnaires (which provided information on; age, sex, weight and height) were administered to the mothers who brought the children to the hospital. The samples were transported to the biological laboratory of University of Abuja, where they were quickly stored in a freezer $\left(-20^{\circ} \mathrm{c}\right)$ until required for parasitological survey.

\section{Wet Preparation}

About $10 \mathrm{~g}$ of the stool specimen was collected and mixed with iodine solution to form a smear. A drop of iodine was also dropped on the microscope slide, covered with cover slip and viewed under the microscope using $\mathrm{x} 40$ objective lens for identification of the parasite. This method was used because iodine stains the nucleus of Entamoeba histolytica properly for easy identification. Floatation method was also employed in analyzing the fecal samples. $10 \mathrm{~g}$ of the stool was placed in a test tube containing saturated salt solution $(0.98 \%)$ which is threequarter full. The test tube was covered and shaked until the stool was completely emulsified. Then a portion of the emulsified stool was placed in a slide and it was covered with a cover slip. The slide was examined under $\mathrm{x} 10$ and $\mathrm{x} 40$ objectives lens for identification of the parasite cyst.

\section{Statistical Analysis}

Prevalence was calculated and expressed as percentage $(\%)$. The results obtained were tested for significance using Chi-square analysis. Significance was determined at $\mathrm{P}<$ 0.05 at $95 \%$ Confidence Interval.

\section{RESULTS}

\section{Prevalence of Entamoeba histolytica by age}

The prevalence of based on the age of participants indicated that Entamoeba histolytica was present $20 \%(\mathrm{n}=3)$ of the participants who were 12 months old and younger, $5.6 \%(\mathrm{n}=1)$ in the age group $13-24$ months had the parasite, $14.7 \%(\mathrm{n}=5)$ in the age group 25 - 36 months also had the parasite, $16 \%(n=1)$ and $11.8 \%(n=2 \%)$ of the participants in the age groups $37-48$ months and $\geq 49$ months respectively were positive for the parasite. Data analysis indicated that there was a positive correlation between prevalence and age of participants $(\mathrm{p}<0.05)$.

\section{Table 1: Prevalence of Entamoeba histolytica by age}

\begin{tabular}{lccc}
\hline Age (months) & Number Tested & Number Positive & Prevalence (\%) \\
\hline$\leq 12$ & 15 & 3.0 & 20.0 \\
$13-24$ & 28 & 1.0 & 3.57 \\
$25-36$ & 34 & 5.0 & 14.7 \\
$37-48$ & 6 & 1.0 & 16.7 \\
$\geq 49$ & 17 & 2.0 & 11.8 \\
\hline
\end{tabular}

Pearson's Chi Square $=36.000 . P$ value $=0.002$

$\mathbf{P}_{\text {value }}$ : Probability value 
Prevalence of Entamoeba histolytica by weight

The weight group $\leq 15 \mathrm{~kg}$ showed a prevalence of $25 \%(\mathrm{n}=6)$, while $16-20$ had a prevalence of $7.1 \%(n=4), 21-25 \mathrm{~kg}$ had prevalence of $10.0 \%(n=2)$. Pearson's chi square indicated that there was a positive correlation between the prevalence and weight $(\mathrm{p}<0.05)$.

Table 2: Prevalence of $E$. histolytica by weight

\begin{tabular}{lccc}
\hline Weight (kg) & Number Tested & Number Positive & Prevalence (\%) \\
\hline$\leq \quad 15$ & 24 & 6 & 25.0 \\
$16-20$ & 56 & 4 & 7.1 \\
$21-25$ & 20 & 2 & 10.0
\end{tabular}

\section{Pearson's Chi Square $=24.000 . P_{\text {value }}=0.0001$}

$\mathbf{P}_{\text {value: }}$ Probability value

\section{Prevalence of Entamoeba histolytica by gender}

Result indicated that females had the highest prevalence $(12.5 \%)$, the male participants had a prevalence of $11.4 \%$. Pearson's chi square analysis indicated that prevalence of Entamoeba histolytica was not dependent of the gender of the participants $(\mathrm{P}>0.05)$.

Table 3: Prevalence of $E$. histolytica by gender

\begin{tabular}{lccc}
\hline Gender & Number Tested & Numb er Positive & Prevalence (\%) \\
\hline Male & 44 & 5 & 11.4 \\
Female & 56 & 7 & 12.5 \\
\hline
\end{tabular}

Pearson's Chi Square $=12.000 . P$ value $=0.05$

$\mathbf{P}_{\text {value: }}$ Probability value

Prevalence of Entamoeba histolytica by Stool characteristics

A prevalence of $13.2 \%$ was observed for participants with watery stool while $16.0 \%$ prevalence was observed for patients who were passing out water stool and bloody stool, $4.5 \%$ passed pout watery stool with mucus. Data analysis showed that the prevalence of Entamoeba histolytica is dependent on the characteristics of stool $(\mathrm{p}<0.05)$.

Table 4: Prevalence of $E$. histolytica by Stool characteristics

\begin{tabular}{lccr}
\hline $\begin{array}{l}\text { Stool Characteristics } \\
(\%)\end{array}$ & Number Tested & Number Positive & Prevalence \\
\hline Watery stool & 53 & 7 & 13.2 \\
Dysentry & 25 & 4 & 16.0 \\
Watery stool with mucus & 22 & 1 & 4.5 \\
\hline
\end{tabular}

Pearson's Chi Square $=24.000 . P_{\text {value }}=0.0002$ 


\section{DISCUSSION}

This study was carried out to determine the prevalence of Entamoeba histolytica in children less than five years of age. The most important outcome of the present study is the description of the epidemiology, clinical features and causative agents of diarrhoea with special emphasis on Entamoeba histolytica associated diarrhoea.

The total prevalence of Entamoeba histolytica in this study is $12 \%(n=12)$. This is lower than the prevalence reported by Adepoju and Ogunleye [4]. They reported that $67.6 \%$ $(n=188)$ of the 278 stool samples they examined were positive for Entamoeba histolytica. Result from this research indicated that there was a positive correlation between the prevalence of Entamoeba histolytica and age of the participants $(\mathrm{p}<0.05)$. The prevalence of Entamoeba histolytica was highest in the age group of $37-48$ months $(16.7 \%)$. This result is in agreement with several literatures that suggest that the prevalence of Entamoeba histolytica should be highest in children.[9,10]. Children of five years and below are said to be the most susceptible group to Entamoeba histolytica infection [11]. The reason for this high prevalence of Enatamoeba histolytica in age group of $1-5$ years may be due to the low immunity against various pathogens as these groups are comparatively less resistant to diseases. [12]

There was no association between gender and prevalence of Entamoeba histolytica. This result agrees with the observations of Dawet [13]. The authors also recorded non- significant difference in distribution of intestinal parasites by gender among primary school children in Jos, Plateau State. Amaechi [14] reported a total prevalence rate of $16.0 \%$. Nyeke [15] however reported a significant prevalence of the parasite in females $(12.3 \%)$. This result is also in collaboration with the findings by Taiwo and Agbolade [16] were females had higher infestation rate $57.5 \%$ than their male counter path $42.5 \%$ in children under five years in Jos.

Pearson's chi square indicated that there was a positive correlation between the prevalence and weight $(\mathrm{p}<0.05)$. The parasite was significant higher in age group $\leq 12$ months. Analysis of result showed that the prevalence of Entamoeba histolytica was dependent on the characteristics of stool $(p<0.05)$. Patients with dysentry had the highest prevalence of the parasite $(16.0 \%)$. These data supports the findings reported by Wanke et al [17] Stool sample examination showed that Entamoeba histolytica associated dysentery was underestimated when dysentery was defined by the gross appearance of blood in stool, however, dysentery was demonstrated in $16 \%$ of cases of Entamoeba histolytica associated diarrhea when the stool samples was examined microscopically for red blood cells. Thus our study 16\% of Entamoeba histolytica associated illnesses are invasive.

\section{Conclusion}

The high prevalence of Entamoeba histolytica infection in children in tropical Africa is a developmental challenge which calls for the assessment of the impact of programmes on millennium development goals in the areas of health. The result of this study revealed a $12 \%$ prevalence of Entamoeba histolytica in children aged 1-59 months. The prevalence of Entamoeba histolytica was highest in patients with dysentry. Age was also observed to be a factor in the prevalence of the parasite as it was observed that the prevalence was highest in the age group $\leq 12$ months. The study concludes that amoebiasis is prevalent in infants visiting the University of Abuja Teaching Hospital with potential health consequences. Owing to the findings of this research, public health interventions such as the provision of clean water, community health education, 
observation of food hygiene, and maintenance of functioning sanitation systems are recommended.

\section{Conflict of interest}

The authors have no conflict of interest to declare

\section{Acknowledgement}

The authors sincerely thank the Academic and non-Academic Staff of the Department of Biological Sciences, University of Abuja and Department of Paediatrics, University of Abuja Teaching Hospital, Abuja. We also appreciate the cooperation of the parents/guardians, and children during the study.

\section{REFERENCES}

1. Bhutta ZA, Das JK, Walker N, Rizvi A, Harry $\mathrm{C}$, et al. Intervention to address deaths from childhood pneumonia and diarrhoea equitably: What works and what cost? 2013; 381: 1417-1429 PubMed.

2. Obadiah HI, Nock IH, Ndams IS, Kogi E, Bugaje MA. Prevalence of Entamoeba histolytica infection in pre-school children in Zaria, Nigeria. Nigeria Journal of Scientific Research. 2011; volume 9\& 10.

3. World Health Organization. Diarrhoea: Why children are the most vulnerable. 2017. Newtimes.co.rw.

4. Adepeju SI, Ogunleye E. Prevalence of Entamoeba histolytica among primary school children in Akure, Ondo State, Nigeria. Journal of Public health and Epidemiology. 2015; 7 (11): 346-351.

5. Benetton ML, Gonclaves AV, Meneghini ME, Silva EF, Carneiro M. Risk factors for infection by the Entamoeba histolytica / Entamoeba dispar complex: an epidemiological study conducted in outpatient clinics in the city of Manaus, Amazon Region, Brazil. Trans R Soc Trop Med Hyg. 2005; 99: $532-40$

6. Ademiluyi H, Odugbesan JA. Sustainability and impact of community water supply and sanitation programmes in Nigeria. An overview. African journal of Agricultural Research.2013;(12): 811-817.

7. Katherina D, Patrik T, Jochen R, Michael M. Diarrhoea prevelance in under five years of age in rural Burundi. An assessment of social and Behavioral factors at the household level. Global action health 2014, 7: 24895. PubMed.

8. Weatherspark: Average weather in Gwavwa lad a, Nigeria. 2016 . https://weatherspark.com

9. Gupta Y, Gupta M, Kohil K, Aneja S. Current drug therapy of protozoan diarrhoea. Indian Journal of pediatrics. 2004; 71:1-4.

10. Huang DB, White AC. An updated review on Cryptosporidium and Giardia. Gastroenterology clinics of North America. 2006; 35(2): 291-314.

11. Haque R, Mondal D, Kirkpatrick BD, Akther S, Farr BM. et al. Epidemiologic and clinical characteristics on acute diarrhoea with emphasis on Entamoeba histolytica infections in pre-school children in an urban slum if Dhaka, Bangladesh. America Journal of Tropical Medicine and Hygiene. 2003; 69(4): 398-495.

12. Haque R, Mondal D, Duggal P, Kabir M, Roy S, Farr BM, Sack RB, Petri WA. Entamoeba histolytica Infection in Children and Protection from Subsequent Amebiasis. Infect Immunity. 2006; 74: 904 - 909 
13. Dawet A, Yakubu DP, Kemkyes MS, Daburum YH. Prevelance of Entamoeba histolytica and Entamoeba dispar among school children in Jos L.G.A, Plateau State, Nigeria. Journal of Parasitology. 2012; 33(1): 77-83.

14. Amaechi EC, Ohaeri CC, Ukpai OM, Nwachukwu PC, Ukoha UK. Prevalence of Entamoeba histolytica among Primary School children in Ukwa West Local Government Area, Abia State, South East, Nigeria. The Bioscientist. 2014;2 (1): 1-7.

15. Nyenke C, Chukwujekwu DC, Stanley HO. Awoibi NK. Prevalence of Intestinal Amoebiasis in Infant and Junior School
Children in Degema General Hospital and Environs. Journal of Applied Science Environmental Management.2008; 12(3) 83 87.

16. Taiwo M, Ak, Agbolade OM. Intestinal helminthiasis among school children in Oru, Ogun state, Nigeria. Nigeria journal of Scientific Research. 2000; 24: 129-136.

17. Wanke C, Butler T, Islam M. Epidemiologic and clinical features of invasive amebiasis in Bangladesh: a case-control comparison with other diarrheal diseases and postmortem findings. 1988; American Journal of Tropical Medicine and Hygiene 38: 614-627 